\title{
Intangible Cultural Heritage Communities in the Network of the Skanzen Hungarian Open Air Museum
}

\author{
Eszter Csonka-Takács \\ Directorate of Intangible Cultural Heritage, Skanzen Hungarian Open Air Museum, Szentendre
}

\begin{abstract}
In Hungary, the professional coordinator of the execution of the 2003 UNESCO convention about the safeguarding of intangible cultural heritage is the Skanzen Hungarian Open Air Museum, celebrating its $50^{\text {th }}$ birthday this year. During its existence, the institution has formed an extensive community and professional network and has become a knowledge center concerning the protection of cultural heritage. The establishment of the Directorate of Intangible Cultural Heritage at the Museum is closely connected to the topic, as it constructed its own national networks based on this background. With respect to the philosophy of the Skanzen, together with the sponsoring cultural ministry, the Directorate created a heritage protection mechanism that focuses on communities retaining and maintaining their identity as a cultural practice, actively engaging them in the unfolding and registration of their intangible cultural heritage. At the same time, it pays attention to continuous communication and options for exchanging experiences. The Hungarian model, which is internationally acknowledged, is exactly ten years old, since Hungary joined the convention in 2006.
\end{abstract}

Keywords: intangible cultural heritage, community, safeguarding, cultural diversity, Hungarian Open Air Museum

The UNESCO convention with the aim of safeguarding the knowledge, skills and expression forms, mediated from generation to generation, created and practiced by communities, groups or individuals and constituting the identity of the abovementioned parties was called into being in 2003 . The convention also strives to work out and execute measures of protection in connection with these at local, national and international level. ${ }^{1}$ The expression intangible cultural heritage $(I C H)^{2}$ was shaped ${ }^{3}$ parallel to the

UNESCO 2003, http://www.unesco.org/culture/ich/en/convention (accessed December 28, 2016).

${ }^{2}$ In French patrimoine culturel immatériel (PCI).

${ }^{3}$ In the denomination and wording of different documents, born during the preparation of the UNESCO convention the process of burnishing and transformation can be followed: Recommendations to the Preservation of Traditional Culture and Folklore (1989), Principles for the Foundation of the System of 'Living Human Treasures'(1996), Action Plan for the Safeguarding of Intangible Cultural Heritage (1999). 
establishment of the convention; its Hungarian counterpart is not a metaphrase of the original meaning, ${ }^{4}$ as a result it needs continuous periphrasis and interpretation. The words untouchable, immaterial and intangible in Hungarian do not reflect the main meanings. The essence of phenomena and practices or traditions in the Hungarian language use considered to be intangible cultural heritage is their community existence, whose basis is provided by the knowledge acquired as the member of the community and the practice performed in the community. However, the community's role does not end with the 'establishing', invigorating and mediating of the heritage, but the 'supervision' of its maintenance too. Every now and then community control selects those practices, individual experiments or innovations that are unacceptable for the members. The community manages the range of participants (if regulated), the way of mediation, the rules of practice and the method of interpretation.

Thus intangible cultural heritage is a process, the practice of living, recognizing and seizing one's own culture from time to time. There is the most direct connection existing between the individual/the community and the heritage-phenomenon: the community and its members are themselves the bearers of heritage. That is why the 2003 convention of the UNESCO was the most intricately determinable topic (on the whole it took 30 years from the first idea till the final version of the international document); this recommendation has raised the most questions and several disputes concerning realization. At the same time it is considered to be the most popular, if the number of states joining the convention and the number of heritage elements introduced or accepted to the representative list pro rata temporis are considered..$^{5}$ As opposed to the practice of preserving primarily material (built, natural and archaeological) heritage, according to the definition of this convention the intangible cultural heritage is the most flexible and changeable, quasi living structure. ${ }^{6}$

Thus it is not by chance that the wording, philosophy, possibilities and tasks provided by operation principles, criteria and the UNESCO practice of execution (more concretely: more intensively in the operation of the Evaluation Body and the Intergovernmental Committee) build upon the communities (groups and individuals), highlight their role and continuously pay attention to involving them into the practice of execution and realization. All this happens without a defined notion of community in the documents of either the convention or the documents of executive commissions.

Concerning the interpretation of intangible cultural heritage and in the institutionalized practice of executing safeguarding measures, there are different directions and solutions among the State Parties ${ }^{7}$. Similarly to this, involving communities in the

\footnotetext{
${ }^{4}$ The Hungarian phrase szellemi kulturális örökség means intellectual cultural heritage.

${ }^{5} 171$ participant countries have joined the Convention for the Safeguarding of the Intangible Cultural Heritage (2003) and there are 430 elements on the intangible cultural heritage list and good practice register. As a comparison the other most popular so-called World Heritage Convention (1972) has been joined by 165 states and there are 1052 world heritage sites on the list. There is an age difference of 30 years between the two conventions.

${ }^{6}$ This flexibility is included in the definition of the convention too: "This intangible cultural heritage... is constantly recreated by communities and groups in response to their environment, their interaction with nature and their history..." UNESCO 2003, Article 2.1.

${ }^{7}$ States Parties are countries which have ratified the Convention. See http://www.unesco.org/culture/ ich/en/states-parties-00024 (accessed December 28, 2016).
} 
handling of heritage shows a variegation too and is characterized by a diversity also typical of intangible cultural heritage (one goal of the convention is to acknowledge cultural diversity ${ }^{8}$ ). In this field, the wording of the document designates principles, recommendations and 'tasks' and the way it is realized, namely the method of execution is assigned to the State Party (even if there is a more concrete and detailed regulation prescribed by the Operational Directives (UNESCO 2016.) besides the generally worded text of the convention, as its practical realization).

The role of communities concerning the execution of the convention raises the question of what aim the joining to the UNESCO's intangible cultural heritage program fulfils in the practice of a certain state's cultural policy. To what extent can it be considered to be a means of national self-representation or cultural heritage industry, or a base and source serving the aims of cultural tourism? The study and interpretation of the international lists, related to the convention can help the understanding of the question. ${ }^{9}$ This paper does not aim to conduct a similar, detailed - and undoubtedly edifying analysis; however, a few tendencies can be traced by examining the 'Representative list of the intangible cultural heritage of humanity.' "Regarding the heritage context it is clear that it extends from communities small in numbers, through minorities possessing national, ethnic conscience or a regional variation of these to the common property of the nation" (KesZer 2005:15). Although this statement was about the 90 elements of the "Masterpieces' ${ }^{10}$ list, constituting the antecedent of the convention, it still applies to the present-day representative list including 366 heritage elements. The fact that the consensual agreement of the involved communities is a compulsory part of the nomination related to the representative list and one of the five criteria of applying is the appropriate, preliminary informing, participation and voluntary approval of involved communities are peculiarities of the system. The document has to prove this with declarations and the description of the informing process.

Thus, the active relation of heritage elements and communities is theoretically a precondition of being accepted to the international lists. Moreover, turning the system upside down, the basis of handling the heritage is the community, and not the heritage itself. Namely, as the first step, the communities bearing the intangible cultural heritage has to be discovered and not 'heritage points' should be designated and with groups assigned to operate them. This reasoning may look unjustified, however, according to the experienced practice so far it poses real questions and problems.

\footnotetext{
8 "promoting respect for cultural diversity and human creativity" UNESCO 2003, Article 2.1.

${ }^{9}$ During the execution of the Convention, concerning the work of the Intergovernmental Committee, the most number of disputes result from the handling of the representative list and the practice of accepting new heritage elements. It has been a tendency for years to withhold, select and slow down the dominance of the representative list's role against the trend. In the practice of some of the countries being nominated to this is almost an exclusive step concerning the execution of the Convention.

${ }^{10}$ Proclamation of the Masterpieces of the Oral and Intangible Heritage of Humanity (2001-2005) http://www.unesco.org/culture/ich/en/proclamation-of-masterpieces-00103 (accessed December 28, 2016).
} 
To the two international lists ${ }^{11}$ related to the intangible cultural heritage convention and including heritage elements the nomination documents are handed in by the State Party. Thus, according to the procedure system and the practice evolved, not the communities apply for the UNESCO lists directly. The State Party hands in not just the nomination, selection is also performed by national intangible cultural committees and bodies created and operated by the state. These institutionalized decision makers have to possess some knowledge or a list from where heritage elements can be chosen for further international application; or as a reverse, they can function as a filter, as they select from the suggestions they receive. Thus one important momentum in the execution of the Convention is the way the State Parties choose heritage elements, later nominated for the UNESCO lists. This question is located on a higher level than the primary function. The method of selecting elements to be incorporated in the list is the consequence of the operation of the system at the national level, the way the relationship with communities bearing heritage elements is organized, moreover of the heritage protection strategy too. We can only protect things about which we know that they exist, what they really are, and have information about their nature.

The abovementioned double-directionality can be considered characteristic on the basis of international examples. There are states where - from the commission of the liable ministry - the representatives of professional institutions (generally it is identical with the membership of the intangible cultural heritage committee) prepare studies in which they draft texts (reminding ethnographical encyclopedia articles) about the heritage elements, designating the involved communities too. These studies are often transformed into thematic monographies. It is a general practice that the ethnographical and folk art institutions of the given countries provide background material and sources of data for the preparation of national inventories. In the cases of some European countries we can witness a direct method of involving communities. Civil organizations themselves can also be the responsible bodies of executing the convention, however there is an example of the possibility to express suggestions for the widest range of people, where anybody can make a suggestion through the Internet, or directly from the community with the proposal of their own heritage. However, these are only rare examples.

The institutionalized, official, moreover 'public administration' character of implementing and handling intangible heritage issues is the general tendency. Furthermore, there is often no direct and continuous relation of parties in the operational system with the participating communities concerned, or local experts or civil organizations. In the abovementioned, with the help of the upside-down system I characterized the situation, when the process begins with a heritage phenomenon interpreted as a constituent symbolic element of national identity and an active community is rendered to this only as the next step.

That is how the discrepancy can occur that resulting from the executing mechanism of the national level, heritage elements of ethnic groups living in national minority cannot be included in the national inventories (and, as a consequence they cannot get into the UNESCO lists, either), as the majority state dedicates the intangible cultural heritage program exclusively to the service of national self-representation. Albeit the convention (similarly to all the other UNESCO documents related to the safeguarding of cultural

\footnotetext{
${ }^{11}$ Representative List of the Intangible Cultural Heritage of Humanity, List of Intangible Cultural Heritage in Need of Urgent Safeguarding.
} 
heritage) is about the registration and as a result, the handling of all heritage elements which can be found in the territory of the State Parties. ${ }^{12}$

Hungary conducts an exemplary practice in this field too: at present among the 30 elements found in the national inventory from among the national minorities living in Hungary Croatian, Slovakian, German and Slovenian heritage elements, a good practice related to the gypsy culture and community practices of different religious denominations can be found. It is due to the nomination mechanism starting from the direction of the community. ${ }^{13}$

Concerning the Hungarian practice, we can say that in the ten years since our accession to the convention (2006) a system of executing the convention has emerged. A body was established handling the heritage issues and the Ministry commissioned the Skanzen Hungarian Open Air Museum as a background institution entrusting it with the coordination of professional tasks, furthermore a system of identification, review and the registration of the intangible cultural heritage was launched. The national committee has been existing since 2008, which has been the Intangible Cultural Heritage Expert Committee of the Hungarian National Commission for four years, in 2009 the Intangible Cultural Heritage Directorate was created, handling the National Inventory (the registration of heritage elements found in the territory of the country). Besides the institutionalized and official structure, determined by the convention, the Directorate has also prepared and operated the expert mechanism of realization.

The Hungarian practice has strived to follow the philosophy of the convention concerning the participating communities from the start. According to the abovementioned, the convention discusses the role of communities and the significance of involving them in the handling of the heritage in general. ${ }^{14}$ The construction of the system of registration at a national level was part of the first steps in Hungary. The question has arisen who creates the list of heritage elements and how, what filters the petition has to go through, who should be the initiator. While the significance of actively involving the communities in the system from the beginning has been evident, the method of realization was a challenge. The thought of preparing a phasing-out system has arisen, in which the community bearing the heritage would have made a proposal to a local/ county level as the first step. However, it seemed to be practical from several aspects,

\footnotetext{
12 "Article 11 - Role of States Parties: Each State Party shall: (a) take the necessary measures to ensure the safeguarding of the intangible cultural heritage present in its territory; (b) among the safeguarding measures referred to in Article 2, paragraph 3, identify and define the various elements of the intangible cultural heritage present in its territory, with the participation of communities, groups and relevant non-governmental organizations. Article 12 - Inventories: 1 . To ensure identification with a view to safeguarding, each State Party shall draw up, in a manner geared to its own situation, one or more inventories of the intangible cultural heritage present in its territory. These inventories shall be regularly updated." (UNESCO 2003)

${ }^{13}$ The inventory and documentation of the Hungarian intangible cultural heritage elements can be found on the website operated by the Directorate: http://szellemikulturalisorokseg.hu/index0_ en.php?name=en_f22_elements

14 "For the purposes of this Convention [...] (b) to ensure respect for the intangible cultural heritage of the communities, groups and individuals concerned" (UNESCO 2003, Article 1. b.) "Each State Party shall: [...] (b) among the safeguarding measures referred to in Article 2, paragraph 3, identify and define the various elements of the intangible cultural heritage present in its territory, with the participation of communities, groups and relevant non-governmental organizations." (UNESCO 2003, Article 11. b.)
} 
if the nominations prepared by the communities from their own initiative are handed in directly at a national level, where independent experts examine them. Concerning the edification of the practice so far it proves to be the best procedure. On the one hand it is an essential factor that petitions arriving at a central institution (thereby the present-day community practice) can be compared and provide wide insight, which also helps the observation of tendencies related to present-day socio-cultural processes. On the other hand, the phase-up system contains the possibility for non-professional aspects coming to the front against local interests. The finally emerging system is operated on the basis of united principles, the handling of heritage is significantly more transparent.

Thus the final decision has created a mechanism during which the communities, creating, maintaining and mediating their heritage and acknowledging it as their own, prepare the nomination documentation, which they hand into a central institution. This latter is the Directorate of Intangible Cultural Heritage operating in the Skanzen, which handles nominations: controls them from formal aspect, sending it out for an expert for a review, makes a summary then puts them in front of the Intangible Cultural Heritage Expert Committee, where it is discussed what heritage elements can be incorporated into the National Inventory. However, the role of the Directorate is much more complex apart from these technical, expert processes. Looking for concerned communities, making contact, communication also belong to the field of activities besides executing administration tasks. Reaching target communities is not always simple.

At this point it is necessary to touch upon the issue concerning the professional execution of the intangible cultural heritage conventions, namely how it fits into the activities of the Hungarian Open Air Museum. The Skanzen as an integrated institution of heritage protection is able to realize the collection, documentation, archiving and functional interpretation of tangible-built-intangible heritage raising questions at the same time. The Skanzen possesses a diversified civil and professional network (see KÁLDY NAGYNÉ BATÁRI 2015 for details), moreover, it functions as a well-working knowledge center from giving folk architectural advice to training teachers and museum managers.

The community and professional network related to the intangible cultural heritage topic has emerged in this light. The Directorate leans on the mediating work of county rapporteurs. The Skanzen created this professional network based on the institutions of the county museum system of the time. By selecting a - mostly ethnographer - expert from each county a group of professionals has been formed, which helps in the mediation of information, the informing and looking up of communities and in the preparation of the nomination document. They provide professional advice for interested communities, organize orientation forums with the participation of the Directorate, making contact between the involved parties. Heritage elements included in the national inventory in the latest years praise the hard work of county rapporteurs.

The number of intangible cultural heritage communities related to the Skanzen are constantly growing. At the moment 30 heritage elements are recorded in the national inventory, which means the participation of thousands of people. Communities get in touch with the Directorate at first when they enquire about the system. Besides rapporteurs the staff of the Directorate also take part in the process of nominating. Professional advice, making suggestions, personal visits, getting acquainted with the community/ heritage directly characterize the process. The administrative decision preparation of the nomination is followed by the organization of the festive announcement of new heritage 
elements included in the inventory. This is the most important, highlighted moment of the community's celebration, during which the representatives of the community bearing the heritage element included in the National Inventory receive the ministerial document of nomination. This has a great role in raising awareness of the significance of the heritage element both inside the community and for the outside world too. It is a frequent phenomenon that being included in the inventory results in the upvaluing of the heritage inside the community. There were cases when the municipal government of towns or younger generations noticed the significance of the living heritage thanks to the nomination. Being included in the national inventory resulted in a positive decision or step in most cases in the local community. The effect of the inventory on the community and the practice of the heritage element can also be observed in almost all cases. The scientific study of this phenomenon in its continuity is an important and edifying task, which is supported by the Directorate by encouraging and leading students to write university essays and thesis.

Regular contact with the communities does not end at this level. One of the most significant and unique element of the Hungarian practice is the fact that it takes care of communities after being included in the inventory too. The Directorate established the company of conscious heritage protectors which consists of communities of the national inventory. It aims to provide support for the members of this huge community concerning the topic of handling heritage, by giving professional and methodological guidance for preparing and executing preservation strategies. The Directorate regularly organizes professional panel discussions for them, where a concrete topic is in the focus (e.g. legal questions of practicing their heritage). The programs, organized by the Directorate, which strive to provide the possibility for communities to present their heritage element together, in one venue, in a representative way are also very important for the communities.

There are two huge festivals annually. In the spring time the Whitsun Heritage Festival takes place, being the international meeting of intangible cultural heritage elements at the same time. This provides the possibility for the communities to introduce themselves in the environment of the Skanzen's original folk architectural monuments. All communities are invited to the program, during which they can present their own heritage for the audience in the yards of individual houses. Craft demonstrations, stage performances are parts of the program, and active involvement of the audience into the participatory activities is a significant feature too. Visitors can try their hands on painting ornamental motifs of Kalocsa, shaping clay on the potters 'wheel of Mezötúr potters', baking 'miller's wafers' characteristic in Borsodnádasd, can turn into a Mohács 'Busó' or a Mezőkövesd 'Matyó' by trying on original pieces of masques and costumes, furthermore they can taste local dishes or can learn folk dances. The direct, interactive encounter with the communities and the experience of cultural diversity at the same time are significant aspects. Visitors can get a taste of the heritage practice of the communities, can experience community identity and the demonstrations of knowledge, skills and expression forms. They can encounter real value and living tradition in an authentic environment.

The other program of great importance is the Cultural Heritage Days, which is part of a European heritage celebration. At these times monuments, locales of built heritage are opened throughout the country. The related national opening ceremony is a festive forum, where the communities included in the national inventory are acknowledged, where this 
fact is declared. The following two-day long program is also a good opportunity for an introduction, thus the Directorate organizes it at differing locales, together, providing opportunity for the communities to introduce themselves.

Both programs are important as they are excellent occasions for communities to meet, to get to know each other's practice of safeguarding their heritage and acquiring mutual experience. It is important for them that they get to know the context, in which they are included by being registered in the national inventory. The 'slogans' and often seemingly 'idealistic targets' of the UNESCO convention become practice this way: the significance of intangible cultural heritage on local, national and international level is really upvalued; the acknowledgment of each other's culture and cultural diversity becomes a reality; creativity and community knowledge become palpable, community identity can be experienced and cultural heritage can be celebrated with the active participation of communities. The communities also formulate these thoughts, feel and understand the significance of the phenomena, and besides, they adhere to introductory participation all the while enjoying it, they are looking forward to meeting the others and are in touch with each other too.

The Hungarian practice seems to be a model on an international level too. The maintenance of the expert network, the consideration of the museum's role as a locale, knowledge base and background institution, and the active involvement of communities from the nomination process till the intangible cultural heritage representation are all examples to be followed. One of the most significant results and examples is monitoring, during which communities actively join the network of the Skanzen, and the Directorate provides new meetings, contact making options and representational possibilities from time to time. I close my paper with citing from a letter dated after one of our programs, written by a member of a community, included recently in the inventory:

"On behalf of the Rajkó Band we thank you for this uncommon welcome, love, kindness, attention, which made clear for us, how wonderful it is to belong to this big family, we can be the members of."

\section{REFERENCES CITED}

\section{CSONKA-TAKÁCs, Eszter}

2010 The Convention for the Safeguarding of the Intangible Cultural Heritage in Service of our Living and Surviving Tradition - Task and Opportunities in Hungary. In Hoppál, Mihály (ed) Sustainable Heritage. Symposium on European Intangible Cultural Heritage 45-50. Budapest: European Folklore Institute.

KÁLDY, Mária - NAGYNÉ BATÁRI, Zsuzsanna

2015 The Hungarian Open Air Museum and its Communities. In Korenchr-Misz, Aniko - LiNDSEY Nikki (eds) Exhibit your culture. Community learning in museums and cultural organizations. CETAID (Community Exhibitions as Tools for Adults' Individual Development) project, 89-95. Budapest: CETAID Partnership. 
KESZEI, András

2005 A megfoghatatlan nyomában [In the Wake of the Incomprehensible]. Budapest: European Folklore Institute (EFI communicationes 16.)

\section{UNESCO}

2003 Convention for the Safeguarding of the Intangible Cultural Heritage, http:// unesdoc.unesco.org/images//0013/001325/132540e.pdf (accessed December 28, 2016).

2016 Operational Directives for the Implementation of the Convention for the Safeguarding of the Intangible Cultural Heritage, http://www.unesco.org/ culture/ich/doc/src/ICH-Operational_Directives-6.GA-PDF-EN.pdf(accessed December 28, 2016).

Eszter Csonka-Takács defended her PhD in Ethnography at the Eötvös Loránd University of Budapest (Hungary) in 2006. She is specializing in folk religion and folk beliefs in the context of its cultural and social functions, as well as cultural heritage studies. She currently works as the director of the Directorate of the Intangible Cultural Heritage, in the Hungarian Open Air Museum, Szentendre. Email address: csonka-takacs.eszter@sznm.hu 